University of Wollongong

Research Online

Faculty of Engineering and Information

Faculty of Engineering and Information

Sciences - Papers: Part A

Sciences

$1-1-2006$

\title{
Distributed generation for minimization of power losses in distribution systems
}

Kashem M. Muttaqi

University of Tasmania, kashem@uow.edu.au

An D. T Le

University of Tasmania, dtale@utas.edu.au

Michael Negnevitsky

University of Tasmania, michael.negnevitsky@utas.edu.au

Gerard Ledwich

Queensland University of Technology, g.ledwich@qut.edu.au

Follow this and additional works at: https://ro.uow.edu.au/eispapers

Part of the Engineering Commons, and the Science and Technology Studies Commons

Research Online is the open access institutional repository for the University of Wollongong. For further information contact the UOW Library: research-pubs@uow.edu.au 


\title{
Distributed generation for minimization of power losses in distribution systems
}

\begin{abstract}
Appropriate size and location of distributed generation (DG) play a significant role in minimizing power losses in distribution systems. This paper represents techniques to minimize power losses in a distribution feeder by optimizing DG model in terms of size, location and operating point of DG. Sensitivity analysis for power losses in terms of DG size and DG operating point has been performed. The proposed sensitivity indices can indicate the changes in power losses with respect to DG current injection. The proposed techniques have been developed with considering load characteristics and representing loads with constant impedance and constant current models, separately. The optimal size and location of DG in a distribution feeder can be obtained through the developed techniques, with minimum effort. The proposed techniques have been tested on a practical long radial system and results are reported. Test results have proven that up to eighty-six percent of real power loss can be reduced with a DG of optimal size, located at optimal place in the feeder.
\end{abstract}

\section{Keywords}

power, minimization, generation, systems, distributed, distribution, losses

Disciplines

Engineering | Science and Technology Studies

\section{Publication Details}

K. A. Kashem, A. D. T. Le, M. Negnevitsky \& G. Ledwich, "Distributed generation for minimization of power losses in distribution systems," in IEEE Power Engineering Society General Meeting, 2006, pp. 1-8. 


\section{Minimising Voltage Deviation in Distribution Feeders by Optimising Size and Location of Distributed Generation}

ARTICLE

Source: OAI

CITATIONS

7
DOWNLOADS

231
VIEWS

98

4 AUTHORS, INCLUDING:

Kashem M. Muttaqi

University of Wollongong

110 PUBLICATIONS 1,031 CITATIONS

SEE PROFILE

Michael Negnevitsky

University of Tasmania

195 PUBLICATIONS 2,023 CITATIONS

SEE PROFILE
Gerard Ledwich

Queensland University of Technology

418 PUBLICATIONS 3,484 CITATIONS

SEE PROFILE 


\section{Minimising Voltage Deviation in Distribution Feeders by Optimising Size and Location of Distributed Generation}

\author{
An D.T. Le, M.A. Kashem, M. Negnevitsky \\ School of Engineering \\ University of Tasmania \\ Sandy Bay, Tasmania, Australia \\ dtale@utas.edu.au
}

\author{
G. Ledwich \\ Electrical and Electronic Systems Engineering \\ Queensland University of Technology \\ Brisbane, Australia \\ g.ledwich@qut.edu.au
}

\begin{abstract}
A new emerging trend of distribution networks is to use small generating units, known as distributed generation (DG), operating in parallel with the main grid. This kind of distribution networks has enabled DG to support power systems in fulfilling their requirements to increase power output as well as quality of power supply. DG has potential to alter power flows, system voltages, and the system performance. In order to maximise benefits from the DG system, proper DG planning is necessary. Determining an optimal DG size and its DG location are critical issues that are addressed in this paper. The main purpose of this research is to maximise voltage support through optimal sizing and location of DG. A new methodology is developed to determine an optimal DG size for a certain DG penetration and an optimal DG location on the distribution feeder for optimising system voltages. The developed technique is tested on a long radial feeder of a practical system and results are reported.
\end{abstract}

Index Terms -- Distributed Generation (DG), Distribution System, Optimal Size, Optimal Location, and Voltage Deviation.

\section{INTRODUCTION}

Utilising of Distributed Generation (DG) to produce electricity has become an increasingly attractive choice for both utility and customers. Traditional options of power utilities to compensate the rapid growth in electricity demand are transmission expansion, substation capacity upgrade and/or DG integration [1]. Among these options, DG appears to be the most perspective one. It does not only relieve the burden of supplying loads from distribution system, but also satisfies the customer's requirements of reliable and continuous power supply, as well as an availability of instantaneous electricity sources when power interruptions occur. Moreover, together with the ongoing efforts to reduce capital investments and operating cost of DG, it is believed that DG can potentially become one of the most effective-cost solutions. In fact, studies have revealed that the electricity generated by DG may account for up to $20 \%$ of all new generation by the year 2010 [2].

For decades, small generation has been used as a backup or stand-by power source to supply electricity for small personal customers during grid power outages. The most common type of DG for this purpose is diesel generation. Nowadays, the recent advances in DG technologies have made this power solution possible not only to serve individual customers but also support the entire network in parallel with the grid. DG technologies can be categorised into two groups: (i) non-renewable energy technologies and (ii) renewable energy technologies. The first group consists of internal combustion engines, gas turbines, micro turbines, etc. The second group produces electricity using renewable energy sources, i.e solar energy, wind energy, tidal energy, wave energy, geothermal energy, bio-energy, etc. Although DG has relatively small size compared with central generation, it is large enough to satisfy electricity requirements of a group of local customers.

Conventional, purpose of distribution systems is to distribute power to the customers. These customers are designed to operate as passive network elements and do not generate any power [3]. However, the current trend of introducing DG into distribution systems makes customers no longer "passive" - they become rather "active". Possibilities of positive impacts of DG include voltage profile improvement, system loss reduction, system stability and reliability improvement, etc. Among all key issues, the choice of the DG size and DG location is of a great importance and is addressed in this paper.

DG sizing and sitting problems have been studied by many researchers recently. In [4], a heuristic cost-benefit approach is developed to define the competitive DG size and location based on the minimisation of investment and operating costs of DGs. A technique to decide DG sizing and sitting has been proposed in [5], which allows distribution system planners to include an optimal size of DG at an optimal location of their design. Authors in [6] have developed a new integrated distribution system planning model based on cost optimisation. Problems related to DG size and location have been discussed in [7]. Genetic Algorithms and Decision Tree Theory are applied in [7] to determine DG siting and sizing for a medium voltage distribution network. In [8], the DG size and location are selected based on the comparison between the performance of several available DGs on system losses and voltage drop. Authors in [9] have established a new method to determine the DG location to minimise the voltage drop and the number of DG supervised.

In this paper, an optimal DG location and its size are determined to maximise improvements of the voltage profile in distribution systems. A technique has been developed based on the voltage deviation and DG 
penetration in the networks to obtain an optimal size and location of DG for any type of distribution systems.

\section{IMPROVEMENT OF NETWORK CONDITIONS BY CURRENT INJECTION FROM DG}

An application of DG can improve the voltage profile of a power system, especially on traditional distribution networks (which are usually radial), where voltages are very close to their lower limits at buses close to remote ends. One of the advantages of the DG usage is that DG can inject both active and reactive power of any combination to improve system conditions and satisfy customer's demands instantaneously.

Let us assume that distribution system consists of $\mathrm{N}$ load buses, where the bus number 1 refers to the source bus and the bus number $\mathrm{N}$ refers to the remote bus at the end of the feeder. A DG will be connected to the feeder and the DG location may be varied to determine its optimal location. The DG integration introduces an internal bus, $\mathrm{N}+1$, in the system. The DG can move along the feeder with this internal bus, without changing the arrangement of the other buses in the system. A current of $\Delta \mathrm{I}_{\mathrm{N}+1}$ is injected into the system from the DG. The resulting voltage changes at all buses in the network due to this current injection are calculated as:

$$
\mathbf{Y}_{\text {bus }} \Delta \mathbf{V}=\Delta \mathbf{I}
$$

where $\mathbf{Y}_{\text {bus }}$ is the impedance matrix for $(\mathrm{N}+1)$ bus system; $\Delta \mathbf{V}$ is the vector of voltage changes for bus 1 to $\mathrm{N}+1 ; \Delta \mathbf{I}$ is the vector of current changes for bus 1 to $\mathrm{N}+1$.

By expanding Eq.(1) into the matrix form, we obtain:

$\left[\begin{array}{c:ccccc}Y_{1,1} & Y_{1,2} & \ldots & Y_{1, N} & Y_{1, N+1} \\ \hdashline Y_{2,1} & Y_{2,2} & \ldots & Y_{2, N} & Y_{2, N+1} \\ \vdots & \vdots & \ddots & \vdots & \vdots \\ Y_{N, 1} & Y_{N, 2} & \ldots & Y_{N, N} & Y_{N, N+1} \\ \hdashline Y_{N+1,1} & Y_{N+1,2} & \ldots & Y_{N+1, N} & Y_{N+1, N+1}\end{array}\right]\left[\begin{array}{c}\Delta V_{1} \\ \hdashline \Delta V_{N+1}\end{array}\right]\left[\begin{array}{c}\Delta I_{1} \\ \vdots \\ \Delta V_{N} \\ \hdashline \\ -\Delta I_{2} \\ \vdots \\ \Delta I_{N} \\ \hdashline \\ \Delta I_{N+1}\end{array}\right]$

Then by partitioning Eq.(2) into sub-matrices, we can obtain:

$\left[\begin{array}{ccc}Y_{A} & Y_{B} & Y_{C} \\ Y_{B}^{T} & Y_{D} & Y_{E} \\ Y_{C}^{T} & Y_{E}^{T} & Y_{F}\end{array}\right]\left[\begin{array}{c}\Delta V_{1} \\ \Delta V_{X} \\ \Delta V_{N+1}\end{array}\right]=\left[\begin{array}{c}\Delta I_{1} \\ \Delta I_{X} \\ \Delta I_{N+1}\end{array}\right]$

where,

$$
\begin{aligned}
& \mathbf{Y}_{\mathbf{A}}=\mathrm{Y}_{1,1} \quad \mathbf{Y}_{\mathbf{B}}=\left[\begin{array}{lll}
Y_{1,2} & \ldots & Y_{1, N}
\end{array}\right] \quad \mathbf{Y}_{\mathbf{C}}=\mathrm{Y}_{1, \mathrm{~N}+1} \\
& \mathbf{Y}_{\mathbf{D}}=\left[\begin{array}{ccc}
Y_{2,2} & \ldots & Y_{2, N} \\
\vdots & \ddots & \vdots \\
Y_{N, 2} & \ldots & Y_{N, N}
\end{array}\right] \quad \mathbf{Y}_{\mathbf{E}}=\left[\begin{array}{c}
Y_{2, N+1} \\
\vdots \\
Y_{N, N+1}
\end{array}\right] \mathbf{Y}_{\mathbf{F}}=\mathrm{Y}_{\mathrm{N}+1, \mathrm{~N}+1} \\
& \Delta \mathbf{V}_{\mathbf{X}}=\left[\begin{array}{c}
\Delta V_{2} \\
\vdots \\
\Delta V_{N}
\end{array}\right] \quad \text { and } \quad \Delta \mathbf{I}_{\mathbf{X}}=\left[\begin{array}{c}
\Delta I_{2} \\
\vdots \\
\Delta I_{N}
\end{array}\right]
\end{aligned}
$$

Because in this test system, the source is connected at bus 1 and the $\mathrm{DG}$ at bus $\mathrm{N}+1$, we have

$$
\begin{aligned}
& \Delta \mathbf{I}_{X}=\mathbf{0}, \quad \Delta V_{1}=\Delta V_{S}, \quad \Delta V_{N+1}=\Delta V_{D G} \quad \text { and } \\
& \Delta I_{N+1}=\Delta I_{D G}
\end{aligned}
$$

When we substitute those values into Eq.(3), we obtain:

$$
\left[\begin{array}{ccc}
\mathbf{Y}_{\mathbf{A}} & \mathbf{Y}_{\mathbf{B}} & \mathbf{Y}_{\mathbf{C}} \\
\mathbf{Y}_{\mathbf{B}}^{\mathbf{T}} & \mathbf{Y}_{\mathbf{D}} & \mathbf{Y}_{\mathbf{E}} \\
\mathbf{Y}_{\mathbf{C}}^{\mathbf{T}} & \mathbf{Y}_{\mathbf{E}}^{\mathbf{T}} & \mathbf{Y}_{\mathbf{F}}
\end{array}\right]\left[\begin{array}{c}
\Delta V_{S} \\
\Delta \mathbf{V}_{\mathbf{X}} \\
\Delta V_{D G}
\end{array}\right]=\left[\begin{array}{c}
\Delta I_{S} \\
\mathbf{0} \\
\Delta I_{D G}
\end{array}\right]
$$

From Eq.(4), we obtain:

$$
\begin{aligned}
& \Delta \mathbf{V}_{\mathbf{X}}=-\mathbf{Y}_{\mathbf{D}}^{-1}\left(\mathbf{Y}_{\mathbf{B}}^{\mathbf{T}} \Delta V_{S}+\mathbf{Y}_{\mathbf{E}} \Delta V_{D G}\right) \\
& \mathbf{Y}_{\mathbf{F}} \Delta V_{D G}=\Delta I_{D G}-\left(\mathbf{Y}_{\mathbf{C}}^{\mathbf{T}} \Delta V_{S}+\mathbf{Y}_{\mathbf{E}}^{\mathbf{T}} \Delta \mathbf{V}_{\mathbf{X}}\right)
\end{aligned}
$$

By substituting $\Delta \mathbf{V}_{\mathbf{X}}$ from Eq.(5) into Eq.(6), we get:

$$
\mathbf{Y}_{\mathbf{F}} \Delta V_{D G}=\Delta I_{D G}-\mathbf{Y}_{\mathbf{C}}^{\mathbf{T}} \Delta V_{S}+\mathbf{Y}_{\mathbf{E}}^{\mathbf{T}} \mathbf{Y}_{\mathbf{D}}^{-I}\left(\mathbf{Y}_{\mathbf{B}}^{\mathbf{T}} \Delta V_{S}+\mathbf{Y}_{\mathbf{E}} \Delta V_{D G}\right)
$$

Voltage at the utility is kept constant, thus there is no change in $\mathrm{V}_{\mathrm{S}}$. In other words, $\Delta \mathrm{V}_{1}=\Delta \mathrm{V}_{\mathrm{S}}=0$. Substituting $\Delta \mathrm{V}_{\mathrm{S}}=0$ into Eq. (7) and rearranging the equation, we obtain:

$$
\Delta V_{D G}=\left(\mathbf{Y}_{\mathbf{F}}-\mathbf{Y}_{\mathbf{E}}^{\mathbf{T}} \mathbf{Y}_{\mathbf{D}}^{-l} \mathbf{Y}_{\mathbf{E}}\right)^{-1} \Delta I_{D G}
$$

Then by substituting Eq.(8) into Eq.(5), we get

$$
\Delta \mathbf{V}_{\mathbf{X}}=-\mathbf{Y}_{\mathbf{D}}^{-l} \mathbf{Y}_{\mathbf{E}}\left(\mathbf{Y}_{\mathbf{F}}-\mathbf{Y}_{\mathbf{E}}^{\mathbf{T}} \mathbf{Y}_{\mathbf{D}}^{-l} \mathbf{Y}_{\mathbf{E}}\right)^{-1} \Delta I_{D G}
$$

The voltage changes from bus 2 to bus $\mathrm{N}$ of the system due to the current injection by the DG can be computed using Eq.(9). Eq.(9) can be rewritten in matrix form as:

$$
\Delta \mathbf{V}_{\mathbf{x}}=\mathbf{a} \Delta I_{D G}
$$

where $\mathbf{a}$ is the coefficient matrix of size N-1, used for calculating voltage changes at bus 2 through bus $\mathrm{N}$.

An introduction of DG into the system results in new system's voltages. The new voltages can be obtained by superposition as follows:

$$
\left[\begin{array}{c}
V_{1}^{\prime} \\
V_{2}^{\prime} \\
\vdots \\
V_{N}^{\prime}
\end{array}\right]=\left[\begin{array}{c}
V_{S} \\
V_{2} \\
\vdots \\
V_{N}
\end{array}\right]+\left[\begin{array}{c}
0 \\
a_{2} \\
\vdots \\
a_{N}
\end{array}\right] \Delta I_{D G}
$$

where $V_{i}$ and $V_{i}^{\prime}$ are voltages of the system without and with DG, respectively.

\section{MAXimising Voltage IMPROVEMENT BY DG}

Modern electrical equipment is designed to operate within a specific range of voltages. Equipment of both utility and customers can only tolerate the fluctuations of voltage in a small period of time. If the voltage remains unstable for a longer time, the equipment has a high probability to get damaged. The acceptable range of 
voltages varies depending on the regulation compliance of different regions in different countries. In Tasmania, for example, the limits of voltage variations are \pm 6 percent in normal operating conditions.

The voltage variations may occur in distribution systems because of many different reasons. Line impedances cause a significant drop in voltage. Moreover, when the available reactive generation cannot meet the growing demand for reactive power at customer's sides, a voltage drop may occur in the system. Also, for long radial feeders, which are very common in rural areas, the transmission of reactive power may not be possible and therefore voltage drop will also be increased at the customer's connection points of loads. Therefore, the voltages of load buses at the remote ends are usually lower than the voltages of load buses close to the utility substation.

Voltage deviation can be defined as the difference between the nominal voltage and the actual voltage. The smaller the deviation of bus voltage from the nominal voltage, the better the voltage condition of the system. A voltage deviation index (TVD) as defined as the sum of the squared value of the absolute voltage difference between the nominal voltage and the actual voltage for all buses in the system:

$$
T V D=\sum_{i=1}^{N}\left|V_{n}-V_{i}\right|^{2}
$$

where $\mathrm{N}$ is the total number of buses, $\mathrm{V}_{\mathrm{n}}$ is the nominal voltage, and $\mathrm{V}_{\mathrm{i}}$ is the actual voltage at bus $\mathrm{i}$.

The DG inclusion into the system can improve voltage profile of the system and reduce the voltage deviation. Let us assume that a DG is included in the system, the new voltage deviation index (TVD') will then become:

$$
T V D^{\prime}=\sum_{i=1}^{N}\left|V_{n}-V_{i}^{\prime}\right|^{2}
$$

By replacing $V_{i}^{\prime}$ by $\left(V_{i}+\Delta V_{i}\right)$, we get:

$$
T V D^{\prime}=\sum_{i=1}^{N}\left|V_{n}-\left(V_{i}+\Delta V_{i}\right)\right|^{2}
$$

By substituting the values of $\Delta V_{i}$ from Eq.(11) into Eq.(14), we obtain:

$$
T V D^{\prime}=\sum_{i=1}^{N}\left|V_{n}-\left(V_{i}+a_{i} \Delta I_{D G}\right)\right|^{2}
$$

The change in the voltage deviation index of the system due to the DG injection can be calculated by subtracting Eq.(15) from Eq.(12), and obtained as

$$
\Delta T V D=\sum_{i=1}^{N}\left[\left|V_{n}-V_{i}\right|^{2}-\left|V_{n}-\left(V_{i}+a_{i} \Delta I_{D G}\right)\right|^{2}\right]
$$

The DG should be designed so that it will minimise the voltage deviation in the system. As can be seen from Eq.(16), the voltage improvement can be achieved by injecting current from the DG. The maximum voltage improvement can be obtained by determining an optimal value of the DG current injection.

\section{DESCRIPTION OF TEST SYSTEM}

A part of the actual practical distribution system shown in Fig. 1 is selected as a test system to determine an optimal size and location of the DG. The test system is derived from a distribution network of Aurora Energy, a distribution utility of Tasmania, which consists of a long radial feeder connected to Smithton substation. Smithton substation is one of 12 response centres in Tasmania. It is located on the North-west of Tasmania. The substation has two incoming feeders of $110 \mathrm{kV}$ and supplies five $22-\mathrm{kV}$ long radial feeders. These are Woolnorth $(48 \mathrm{~km})$, Arthur River (64 km), Edith Creek (14 km), Roger River $(28 \mathrm{~km})$, and Smithton Township (300m). Fig.1 shows one-line diagram of the substation.

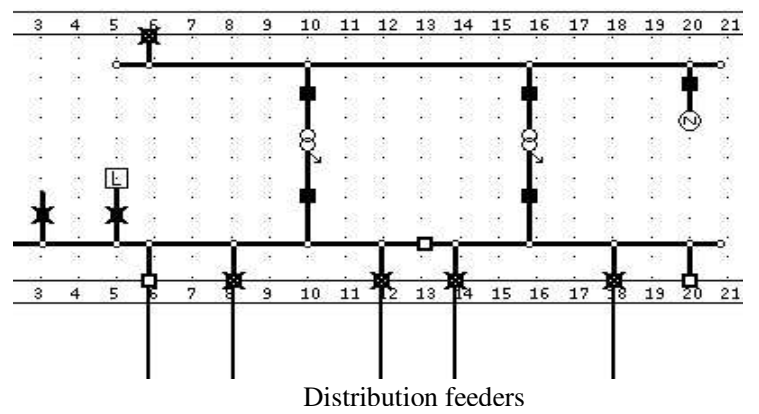

Figure 1: Smithton substation's one-line diagram

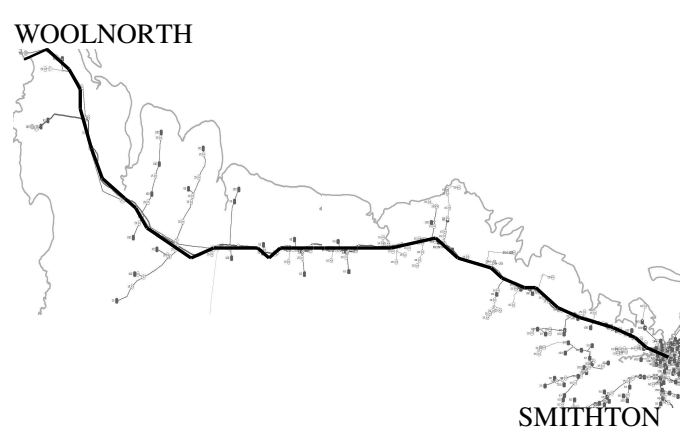

Figure 2: Smithton - Woolnorth test feeder

The 48-km radial feeder from Smithton substation to Woolnorth shown in Fig. 2 is chosen as a test feeder to validate the developed technique. The test feeder consists of 69 load buses. The line impedance of the feeder is $Z_{1}=0.6672+\mathrm{j} 0.3745 \Omega / \mathrm{km}$. Nominal substation voltage $V_{S}$ is $22 \mathrm{kV}$ and Thevenin source impedance $Z_{S}$ is $0.7278+j 2.6802 \Omega$. The total load of the feeder is 2 MVA. For simplification, we assume that the feeder has uniformly distributed loads.

\section{Simulation ReSUlts AND Discussions}

Simulations are conducted in MATLAB 7.0 with a DG integrated in the test system to investigate an improvement in the voltage profile of the system. The MVA base of 1MVA and voltage base of $22 \mathrm{kV}$ are used in the simulation. The DG is moved along the feeder to determine its optimal location. Also, the level of the DG penetration is increased from minimum to maximum to obtain an optimal size of the DG. The value of the voltage deviation index of the system without the DG was 0.23973 . It is known that when the system has high $\mathrm{R} / \mathrm{X}$ ratio of line, it requires mostly real power for 
voltage improvement [10]. For the test system, the ratio of $\mathrm{R} / \mathrm{X}$ is 1.78 . Therefore, for simplicity, we can chose only real power injections from the DG. Thus, the current injection from the DG has the same phase as the phase of the local voltage at the connection point.

\subsection{EFFECTS OF THE DG LOCATION ON THE SYSTEM VOLTAGE}

Previous studies have proven that the DG location is one of the most important issues in distribution system planning. A proper location of the DG will maximise its potential support for improving the system voltage profile. Simulations are carried out to determine the DG location, which provides the minimum voltage deviation index for a required level of the DG penetration.

Consider a DG that can support the full load in the system. Such situation is defined as the $100 \%$ DG penetration. Fig. 3 shows the voltage deviation index of the system. The index value is calculated with the DG placed at each load bus, one at a time.

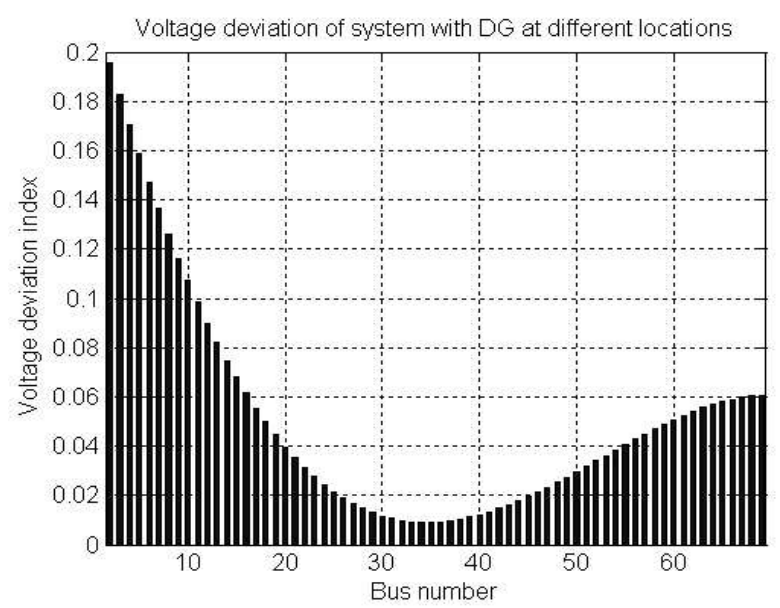

Figure 3: Voltage deviation with the $100 \%$ DG penetration

The minimum value of the voltage deviation index of the system is found to be 0.00903 , which corresponds to the DG located at bus 35 .

Simulations are also carried out with different levels of the DG penetration. Optimal DG locations for different DG penetrations are presented in Table 1.

Table 1: Optimal DG location for different levels of DG penetration

\begin{tabular}{|c|c|c|}
\hline DG penetration & Optimal location & Distance (km) \\
\hline $10 \%$ & 69 & 48.0 \\
$20 \%$ & 69 & 48.0 \\
$30 \%$ & 69 & 48.0 \\
$40 \%$ & 69 & 48.0 \\
$50 \%$ & 69 & 48.0 \\
$60 \%$ & 61 & 42.3 \\
$70 \%$ & 52 & 35.8 \\
$80 \%$ & 45 & 30.8 \\
$90 \%$ & 39 & 26.5 \\
$100 \%$ & 35 & 23.6 \\
\hline
\end{tabular}

The results show that with the smaller penetration, system voltages are improved the most when the DG is located at the end of the feeder. This can be explained by the fact that the voltage at the remote load bus has the lowest value, and therefore more voltage support is needed. When the level of DG penetration is increased, an optimal DG location is moved toward the middle of the feeder. This reveals that when the DG penetration is high, it is more effective to place the DG away from the remote end, so that all load buses in the system can benefit from the DG.

\subsection{EFFECT OF DG Size on System Voltage}

Different DG sizes provide different levels of voltage support to the system. Our purpose is to determine the proper DG size to maximise the system voltage improvement, which is evaluated by voltage deviation index. Simulations are carried out via increasing the DG size at different locations of the system.

Fig.4 examines how the system has responded to varying the DG size. Load buses selected to test the performance of DG are buses 68,61, 54, 47 and 40. From this graph we can see that, the changes of the system voltage deviation index due to the changes of the DG penetration level has a parabolic trend. As the output of the DG current increases, the voltage deviation index decreases. However, it will start to increase after a certain level of the DG penetration. The point where the voltage deviation obtains its minimum value is defined as the optimal size for maximum voltage improvement. Also, the importance of DG location is clearly illustrated in Fig.4 - different DG locations give different optimal DG sizes.

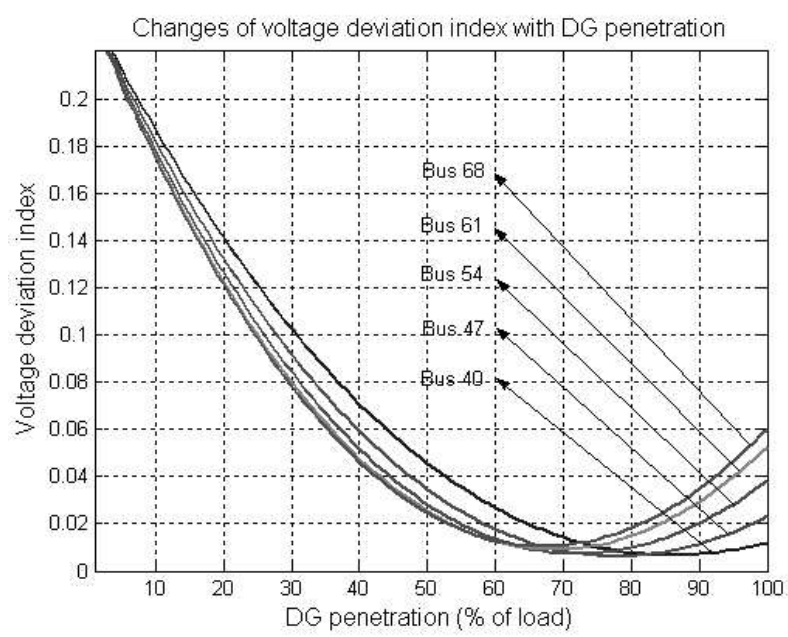

Figure 4: Changes of voltage deviation with increasing DG penetration

The minimum voltage deviation index can also be obtained for different DG locations and different DG penetration. The results are shown in Fig.5. The threedimensional graph here represents the minimum voltage deviation index of the system, corresponding to the respective DG penetration and DG location. From Fig.5, we observe that the improvement of the system voltages does not only depend on the DG size, but also on the DG location. Maximum voltage support by the $\mathrm{DG}$ is achieved with the $80 \%$ DG penetration at bus 45 , which is the optimal DG location.

Eq.(16) is used to determine an optimal DG size at a specified location. Results are shown in Table 2. Since 
the results obtained in the previous part indicate that the DG operates more effectively when it is located at a load bus close to the end of the feeder, we only consider buses from 40 to 69 .

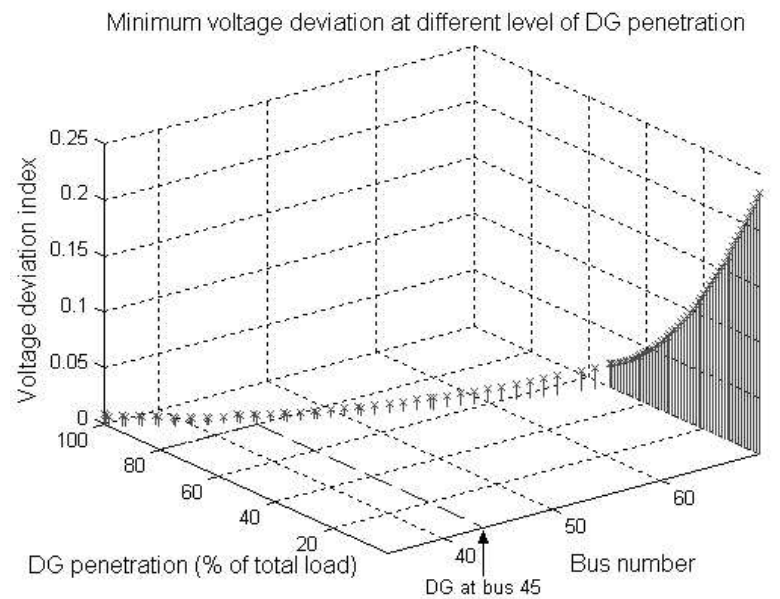

Figure 5: Minimum voltage deviation index at different levels of the DG penetration

Table 2: Optimal DG size for specified buses

\begin{tabular}{|c|c|c|c|c|}
\hline Bus & $\begin{array}{c}\text { Distance } \\
(\mathrm{km})\end{array}$ & $\Delta I_{D G, \max }^{T V D}$ & Min TVD & $\Delta$ TVD \\
\hline 40 & 27.2 & 1.65 & 0.00666 & 0.23307 \\
41 & 27.9 & 1.62 & 0.00648 & 0.23325 \\
42 & 28.7 & 1.60 & 0.00635 & 0.23338 \\
43 & 29.4 & 1.58 & 0.00625 & 0.23348 \\
44 & 30.1 & 1.55 & 0.00620 & 0.23353 \\
$\mathbf{4 5}$ & $\mathbf{3 0 . 8}$ & $\mathbf{1 . 5 3}$ & $\mathbf{0 . 0 0 6 1 7}$ & $\mathbf{0 . 2 3 3 5 6}$ \\
46 & 31.5 & 1.51 & 0.00619 & 0.23354 \\
47 & 32.2 & 1.50 & 0.00624 & 0.23349 \\
48 & 33.0 & 1.48 & 0.00631 & 0.23342 \\
49 & 33.7 & 1.46 & 0.00642 & 0.23331 \\
50 & 34.4 & 1.45 & 0.00656 & 0.23317 \\
51 & 35.1 & 1.43 & 0.00671 & 0.23302 \\
52 & 35.8 & 1.42 & 0.00689 & 0.23284 \\
53 & 36.5 & 1.40 & 0.00709 & 0.23264 \\
54 & 37.3 & 1.39 & 0.00731 & 0.23242 \\
55 & 38.0 & 1.38 & 0.00754 & 0.23219 \\
56 & 38.7 & 1.37 & 0.00779 & 0.23194 \\
57 & 39.4 & 1.36 & 0.00804 & 0.23169 \\
58 & 40.1 & 1.35 & 0.00830 & 0.23143 \\
59 & 40.8 & 1.34 & 0.00857 & 0.23116 \\
60 & 41.6 & 1.33 & 0.00883 & 0.23090 \\
61 & 42.3 & 1.33 & 0.00910 & 0.23063 \\
62 & 43.0 & 1.32 & 0.00934 & 0.23039 \\
63 & 43.7 & 1.31 & 0.00959 & 0.23014 \\
64 & 44.4 & 1.31 & 0.00981 & 0.22992 \\
65 & 45.1 & 1.30 & 0.01001 & 0.22972 \\
66 & 45.9 & 1.30 & 0.01018 & 0.22955 \\
67 & 46.6 & 1.30 & 0.01032 & 0.22941 \\
68 & 47.3 & 1.30 & 0.01043 & 0.22930 \\
69 & 48.0 & 1.29 & 0.01048 & 0.22925 \\
\hline & & & & \\
\hline
\end{tabular}

From Table 2, we can see that the minimum voltage deviation index (TVD) or the maximum voltage deviation reduction ( $\triangle$ TVD) is obtained when the $\mathrm{DG}$ is located at bus 45 with the DG output current of 1.53 p.u., which corresponds to the approximately $80 \%$ DG penetration. It can also be noted that the DG at different sites on the feeder gives different levels of voltage support to the system (local maximum values). Fig.6 shows how the DG location affects the voltage deviation index and the voltage deviation reduction of the system.

An optimal DG size is changing with the changes in DG location, which is shown in Fig.7. When the DG is located closer to the remote end, the optimal DG sizing is decreasing. The proposed method can also be used to define an optimal DG size for a specific DG location. In reality, a fixed DG location is a common practice, especially with those DGs that require large space for installation or need to be sited near the energy resources.

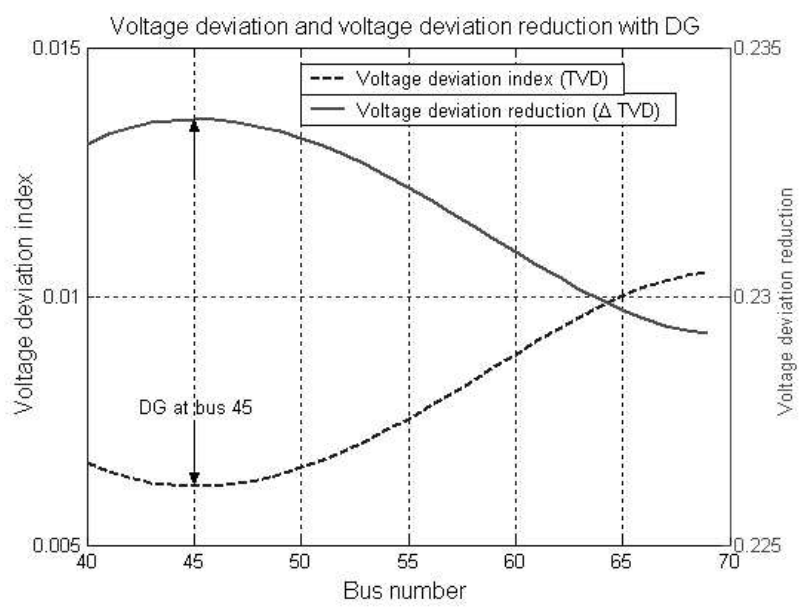

Figure 6: Voltage deviation index and voltage deviation reduction with DG located at different buses

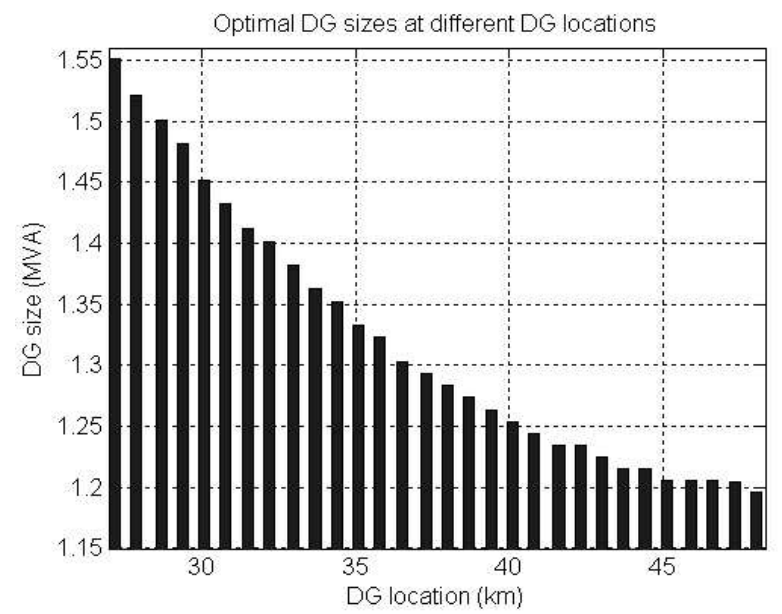

Figure 7: Optimal DG sizes for different DG locations

Fig.8 shows the voltage profile of the feeder with and without the DG. System without DG has the voltage profile of a typical radial system, where the voltage is decreasing along the feeder. The voltages at some downstream load buses drop below the acceptable range of 0.94 p.u. The lowest voltage of 0.926 p.u. occurs at the remote load bus. However, the voltage profile of the system with DG shows a significant improvement in voltage. The voltages of all sections in the feeder are within the voltage limit. Lowest voltage for the system with DG integration is 0.992 p.u.

Fig.9 illustrates the reduction in voltage deviation at each load bus in the system. The DG has effectively reduced the voltage deviations and keeps the voltages of all load buses close to the nominal value.

It is desirable to keep voltages at all sections as close to 1.0 p.u. as possible. However, such approach can only be used when the cost of DGs is not an issue. The DG cost can be considerably reduced by operating the network with acceptable voltage range of $(1 \pm 0.06$ p.u. $)$. 
Depending on the requirements of the utility and customers, different levels of lower limit of the voltage may be required. Table 3 provides optimal sizes and locations of the DG for different reference voltages. The DG size is reduced when the reference voltage is reduced. The last column in Table 3 shows the DG placement as a ratio of the distance of the DG from the substation to the total feeder length.

Table 3: DG sizes and locations for different reference voltage levels

\begin{tabular}{|c|c|c|c|c|c|}
\hline \multirow{2}{*}{$\begin{array}{c}\text { Reference } \\
\text { voltage }\end{array}$} & \multicolumn{2}{|c|}{ DG size } & \multicolumn{3}{c|}{ DG location } \\
\cline { 2 - 6 } 0.94 p.u. & 175.8 & $9 \%$ & 67 & $46.6 \mathrm{~km}$ & $97.1 \%$ \\
\hline 0.95 p.u. & 312.5 & $16 \%$ & 64 & $44.4 \mathrm{~km}$ & $92.5 \%$ \\
\hline 0.96 p.u. & 476.2 & $24 \%$ & 60 & $41.6 \mathrm{~km}$ & $86.7 \%$ \\
\hline 0.97 p.u. & 656.6 & $33 \%$ & 57 & $39.4 \mathrm{~km}$ & $82.1 \%$ \\
\hline 0.98 p.u. & 853.9 & $43 \%$ & 53 & $36.5 \mathrm{~km}$ & $76.0 \%$ \\
\hline 0.99 p.u. & 1103.6 & $55 \%$ & 48 & $33.0 \mathrm{~km}$ & $68.8 \%$ \\
\hline
\end{tabular}

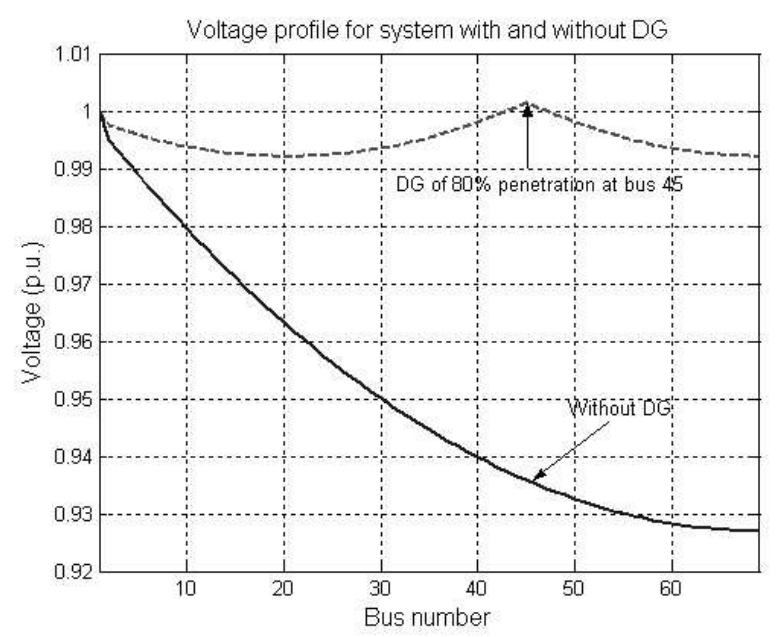

Figure 8: Voltage profile of system with and without DG

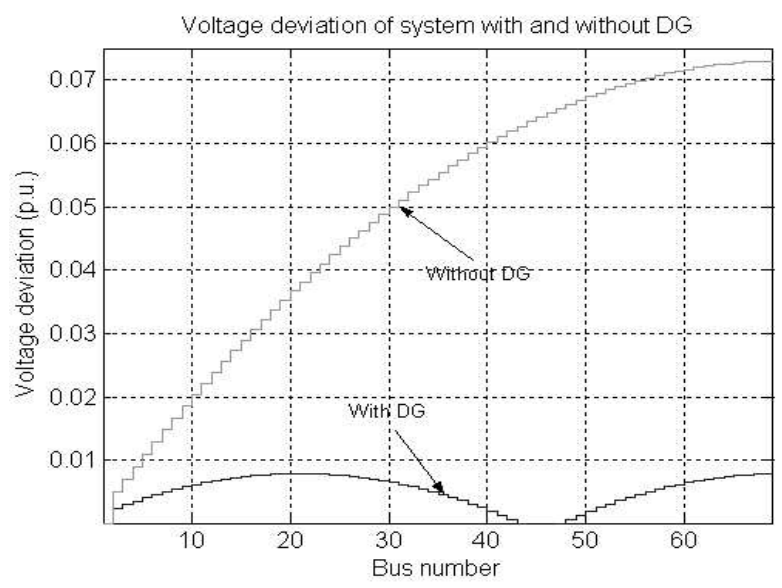

Figure 9: The voltage devation for each load bus in the system before and after DG inclusion

\section{Conclusions}

In this paper, improvement of the system's voltage profile by utilisation of DGs is discussed. A novel approach has been developed to determine an optimal DG size and a DG location to maximise the voltage support in distribution systems. Voltage variations of the system are evaluated by the voltage deviation index. By using the proposed technique, the voltage deviation can be improved considerably for any distribution systems. Also, a new method to compute the voltage improvement at each load bus in the system with DG is introduced. Simulations are carried out with a practical system to verify the validity of the proposed method. Optimal DG sizes for minimising the system voltage deviations are computed for different candidate DG locations, and thus the optimal location can be selected. The outcome of this research helps not only to determine the optimal DG sitting and sizing in the system, but also to determine the optimal DG sizing for a specific location of DG.

\section{ACKNOWLEDGMENTS}

This research has been funded by the Australian Research Council under ARC Linkage Grant K0014223 "Integration of Distributed and Renewable Power Generation into Electricity Grid Systems". The authors also would like to thank Aurora Energy personnel for providing data for case studies.

\section{REFERENCES}

[1] R.E. Brown, Pan Jiuping, Feng Xiaoming, and K. Koutlev, "Siting Distributed Generation to Defer T\&D Expansion", Transmission and Distribution Conference and Exposition, 2001, IEEE/PES, 28 Oct.-2 Nov. 2001, Vol. 2, pp. 622 627.

[2] P.P. Barker, and R.W. de Mello, "Determining the Impact of Distributed Generation on Power Systems: Part1 - Radial Distribution Systems", 2000 IEEE Power Engineering Society Summer Meeting, Seattle, Washington, 2000, pp. 1645-1656.

[3] S.K. Salman, "The Impact of Embedded Generation on Voltage Regulation and Losses of Distribution Networks", IEE Colloquium on the Impact of Embedded Generation on Distribution Networks (Digest No. 1996/194), London, 15 Oct. 1996, pp. 2/1 - 2/5.

[4] W. El-Khattam, K. Bhattacharya, Y. Hegazy, and M.M.A. Salama, "Optimal investment planning for distributed generation in a competitive electricity market", IEEE Transactions on Power Systems, Aug. 2004, Vol. 19, Issue 3, pp. $1674-1684$.

[5] G. Celli, E. Ghiani, S. Mocci, and F. Pilo, "A multiobjective evolutionary algorithm for the sizing and siting of distributed generation", IEEE Transactions on Power Systems, May 2005, Vol. 20, Issue 2, pp. $750-757$.

[6] W. El-Khattam, Y.G. Hegazy, and M.M.A. Salama, "An integrated distributed generation optimization model for distribution system planning", IEEE Transactions on Power Systems, May 2005, Vol. 20, Issue 2, pp. 1158 - 1165.

[7] G. Carpinelli, G. Celli, F. Pilo, and A. Russo, "Distributed generation siting and sizing under uncertainty", 2001 IEEE Porto Power Tech Conference, Porto, 10-13 Sept. 2001, Vol. 4.

[8] C.L.T. Borges, and D.M. Falcao, "Impact of distributed generation allocation and sizing on reliability, losses and voltage profile", 2003 IEEE Bologna Power Tech Conference, Bologna, Italy, 23-26 June 2003, Vol. 2.

[9] R. Caire, N. Retiere, E. Morin, M. Fontela, and N. Hadjsaid, "Voltage management of distributed generation in distribution networks", Power Engineering Society General Meeting, 2003, IEEE, 13-17 July 2003, Vol. 1, pp. $282-$ 287.

[10] M.A. Kashem, and G. Ledwich, "Distributed generation as Voltage support for single wire Earth return systems", IEEE Transactions on Power Delivery, July 2004, Vol. 19, Issue 3, pp. $1002-1011$. 